RAEIC, Revista de la Asociación Española de Investigación

\title{
O Jornalismo em saúde e as fontes de informação: o caso da COVID-19 em Portugal
}

Health Journalism and Information Sources: The Case of COVID-19 in Portugal

Gomes, Sofia

Universidade do Minho (UMinho) sofiagomes 11@hotmail.com

Forma de citar este artículo:

Gomes, S. (2020). "O Jornalismo em saúde e as fontes de informação: o caso da COVID-19 em Portugal", RAEIC, Revista de la Asociación Española de Investigación de la Comunicación, vol. 7, núm. 14, 127-149.

https://doi.org/10.24137/raeic.7.14.6

\section{Resumo:}

Em dezembro de 2019, deu-se início a uma crise de saúde pública com surgimento de uma pandemia resultante do novo Coronavírus. O desconhecimento por parte da comunidade científica sobre este vírus gerou um interesse especial na sociedade e uma mudança no comportamento dos meios de comunicação social. 
Equacionando o poder dos média e dando especial atenção às fontes de informação, este trabalho procura promover uma melhor compreensão da cobertura mediática deste vírus, através da análise dos textos noticiosos publicados em quatro jornais portugueses de expressão online: o Jornal de Notícias, o Público, o Observador e o Notícias ao Minuto. Desta seleção resultaram 280 artigos que revelaram uma forte presença de fontes externas ao campo da saúde. Concluiu-se, ainda, que o Jornalismo tem uma responsabilidade social acrescida neste contexto pandémico. São resultados preliminares de uma investigação que se quer mais desenvolvida no tempo e no espaço.

Este trabalho foi apoiado por fundos nacionais através da FCT -Fundação para a Ciência e a Tecnologia, I.P., no âmbito do Financiamento Plurianual do Centro de Estudos de Comunicação e Sociedade 2020-2023 (que integra as parcelas de financiamento base, com a referência UIDB/00736/2020, e financiamento programático, com a referência UIDP/00736/2020).

Palavras-chave: Jornalismo em Saúde, Fontes de Informação, COVID-19, Coronavírus.

\section{Abstract:}

In December 2019, a public health crisis began with the emergence of a pandemic resulting from the new coronavirus. The lack of knowledge on the part of the scientific community about this virus has generated a special interest in society and a change in the behavior of the media.

Equating the power of the media and paying special attention to the sources of information, this work seeks to contribute to a better understanding of the media coverage of this virus through the analysis of news texts published in four Portuguese newspapers of online expression: Jornal de Notícias, Público, Observador and Notícias ao Minuto. This selection resulted in 280 articles that revealed a strong presence of sources external to the health field. It was also concluded that Journalism has an increased social responsibility in this pandemic context. These are preliminary results of an investigation that wants to be further developed in time and space. 
This work is funded by national funds through Fundação para a Ciência e a Tecnologia, I.P., within the scope of the multi-annual project of the Communication and Society Research Centre 2020-2023 (which integrates base funding, with the reference UIDB/00736/2020, and programmatic funding, with reference UIDP/00736/2020).

Keywords: Health Journalism, Sources of Information, COVID-19, coronavirus.

\section{INTRODUÇÃO}

Em dezembro de 2019, o mundo assistiu ao início de uma crise de saúde pública: o surgimento de um novo Coronavírus (SARS-CoV-2). COVID-19, a doença resultante deste vírus, provoca sintomas semelhantes aos de uma gripe ou, em casos mais graves, aos de uma pneumonia. Os primeiros doentes identificados foram associados a um mercado na cidade chinesa de Wuhan. Apesar de este ter sido encerrado logo no início de janeiro de 2020, não foi possível travar a progressão da doença, que acabou por despoletar uma epidemia mundial, ou pandemia, como definiu a Organização Mundial de Saúde (OMS) para se referir a este surto repentino (Vaughan e Tinker, 2009).

Em poucos meses, a COVID-19 alastrou-se por mais de 180 países (Valero-Cedeño, MinaOrtiz, Veliz-Castro, Merchán-Villafuerte e Perozo-Mena, 2020). Em Portugal, os primeiros casos foram registados no início de março, no Norte do país (DGS, 2020).

A progressão deste novo Coronavírus à escala mundial mereceu a rápida atenção dos média, que imediatamente alteraram as suas agendas e passaram a trabalhar quase exclusivamente sobre este assunto.

A presente investigação surge, pois, no seio deste contexto pandémico e tem como objetivo perceber o processo de disseminação da informação sobre a COVID-19 em Portugal. Equacionando o poder dos média e dando especial atenção às fontes de informação, este trabalho procura contribuir para uma melhor compreensão da cobertura mediática deste vírus, através da análise dos textos noticiosos publicados em 
quatro jornais portugueses de expressão online: o Jornal de Notícias, o Público, o Observador e o Notícias ao Minuto.

Trata-se de uma investigação em curso, pelo que o presente artigo aponta para resultados preliminares de um trabalho que se quer mais desenvolvido no tempo e no espaço.

\section{DA SAÚDE E O JORNALISMO}

A Saúde é uma área de investigação em valorização crescente na sociedade ocidental contemporânea, ramificando-se em diversas subáreas de estudo. Prova desta evolução é o aumento constante da atenção dada às imensas atividades relacionadas com a saúde. O jornalismo não é exceção. Os média são os principais fornecedores de informação para a população em geral, pelo que estudar o Jornalismo adquire um papel fundamental quando o objetivo é compreender as lógicas de recolha, produção e transmissão de conhecimento (Gomes, 2019).

Numa definição curta, a Organização Mundial da Saúde (OMS) define saúde como "o estado do mais completo bem-estar físico, mental e social e não apenas a ausência de enfermidade" ${ }^{1}$. Scott Ratzan (2002), investigador americano reconhecido pelo seu contributo no campo da Comunicação em Saúde, defende que a saúde é uma componente essencial da sociedade civil, aproximando-a da própria conceção de existência. Nesta ordem de ideias, evidencia-se, a necessidade de equacionar o conceito de saúde em função do seu contexto social, pelo que a saúde do indivíduo abarca um amplo leque de significados, desde uma conceção marcadamente técnica a uma conceção moral e filosófica (Naidoo e Wills, 1998).

Por seu turno, também o Jornalismo foi sempre vulnerável a fatores tecnológicos, económicos e sociais, mas atualmente encontra-se num estado de fluxo e ultrapassa mudanças estruturais. Estas alterações trazem consigo consequências no papel do Jornalismo enquanto prática, produto e profissão (Pavlik, 2001; Spyridou, Matsiola, Veglis, Kalliris e Dimoulas, 2013). Face a estas modificações, o Jornalismo vê-se obrigado

\footnotetext{
${ }^{1}$ Ver https://www.who.int/governance/eb/who constitution sp.pdf?ua=1
} 
a mudar. E é isso que tem procurado fazer. Tenta ser cada vez mais atrativo e responder às necessidades da audiência. Lado a lado com a informação, há (quase) sempre uma preocupação com o interesse do público. A sua razão de ser reflete-se no exercício da cidadania e na construção da memória pública, sustentada na participação cívica (Martins, 2010). Desta forma, o Jornalismo representa uma delicada combinação entre a responsabilidade pública e a iniciativa privada (Bardoel e d'Haenens, 2004; Eide, 2014; Elliott, 2015). É nesta relação que ganha força a ideia de contrato social do Jornalismo.

Seja qual for a natureza de um contrato, este determina um vínculo entre duas (ou mais) partes. Através de um contrato, as partes passam a ter responsabilidades, assim como direitos (Marvin e Meyer, 2005; Sjф vaag, 2010). Seguindo esta lógica, as responsabilidades não podem ser consideradas mais importantes que os direitos, precisamente por causa da premissa da reciprocidade do contrato ( $\mathrm{j} \emptyset$ vaag, 2010). Assim, a metáfora de uma relação contratual entre a sociedade e os média implica que estes estejam envolvidos numa troca complexa: o Jornalismo tem a responsabilidade de prestar serviços de grande valor à sociedade, enquanto esta serve de fonte de informação para as notícias a publicar (Eide, 2014; Raaum, 1986, 1999; SjØvaag, 2010; Strömbäck, 2005).

Perante esta importância do Jornalismo junto da sociedade, cria-se naturalmente uma ponte para a área especializada da saúde. Na sua essência, o Jornalismo especializado procura, transmitir e explicar informações relativas a temáticas específicas, ultrapassando a sua função no debate democrático e a sua função crítica (Marcotte e Sauvageau, 2006).

A especialização do Jornalismo pode ser pensada em diferentes perspetivas: relativa aos temas, assim como aos meios de comunicação (Tavares, 2007). No que diz respeito à especialização por temas, faz-se uma aproximação à Teoria da Tematização, apresentando-se uma nova conceção de opinião pública, sendo esta o resultado de uma seleção conduzida pelo Jornalismo de temáticas (Tavares, 2007, 2009). Relativamente à especialização por meios de comunicação, esta acontece em função do meio utilizado para transmitir a informação (televisão, rádio, internet). 
Esta crescente tendência para um jornalismo especializado encontra explicação em lógicas cada vez mais diversas de produção e de consumo da informação. É, também, nesta especialização que se estabelece a dependência ou independência do jornalista relativamente ao meio para o qual trabalha e é, ainda, nesta especialização que se assegura o cumprimento da função social do Jornalismo.

O Jornalismo em saúde é, portanto, um modo de jornalismo especializado. Através da informação que torna pública, transmite conhecimento sobre assuntos de saúde à população, nem sempre detentora de grande conhecimento sobre esta área do saber. Por isso mesmo, esta audiência leva muito em consideração as notícias que recebe dos média, para que, assim, possa tomar decisões informadas. Neste contexto, é possível afirmar que o Jornalismo em saúde tem um papel crucial na literacia para a saúde do seu público (Friedman, Tanner e Rose, 2013; Hinnant e Len-Rios, 2009; Wilson, Robertson, McElduff, Jones e Henry, 2010; Tanner, Friedman e Zheng, 2015). Contudo, para que isso seja possível, o público necessita de informações claras e precisas (Wilson et al., 2010).

Com toda esta responsabilidade, o Jornalismo em saúde procura cobrir um contexto muito amplo e complexo, que envolve não só a investigação biomédica e clínica, mas também assuntos de saúde pública, bem-estar, estilos de vida, políticas de saúde, entre outras (Hallin e Briggs, 2014; Schwitzer, 2009). Além deste campo alargado de conhecimento e sua consequente carga de trabalho, o Jornalismo em saúde, tem também visto os seus recursos humanos diminuídos. Em tempo de pandemia, como a de COVID-19, estes fatores agravam-se consideravelmente e o panorama aponta, portanto, para sérias preocupações relativamente ao exercício do Jornalismo sobre saúde.

\section{O PODER DAS FONTES DE INFORMAÇÃO}

Apesar das preocupações identificadas atrás, o futuro do Jornalismo em saúde passará, certamente, pelas funções que os jornalistas adotarem e pela relação estabelecida entre jornalistas, cientistas e profissionais de saúde (Schwitzer, 2010). A importância desta relação advém do facto de o processo de construção da notícia ser constituído por 
diversos protagonistas, nomeadamente, os jornalistas e as fontes de informação. As fontes de informação podem ser adquirir formas distintas. Sejam elas individuais ou coletivas, são a matéria-prima para o desenrolar do processo de produção noticiosa. Desta forma, a construção da notícia requer um conjunto de negociações e uma estreita cooperação entre fontes e jornalistas (Lewis, Williams e Franklin, 2008), pois o conteúdo das notícias depende diretamente da informação que as fontes proporcionam aos média (Sigal, 2008).

A interação entre jornalistas e fontes de informação passa, então, por um conjunto de questões como o tipo de fonte e o conhecimento da informação que lhe confere o papel de fonte, a (in)dependência do jornalista em relação à fonte e a existência de objetivos comuns. Nesta relação, importa, perceber que todas as fontes de informação têm interesses, nomeadamente o de influenciar a agenda mediática e o processo de construção noticiosa em prol das suas conveniências (Lopes, Ruão, Marinho e Araújo, 2011).

No campo da saúde, a esta relação jornalista-fonte são adicionados constrangimentos específicos. Com o objetivo de simplificar a informação de modo a que o público a entenda, os jornalistas desvalorizam dados que lhes parecem irrelevantes, mas que, para os cientistas, por vezes, fazem toda a diferença (Allgaier, Dunwoody, Brossard, YinYueh e Peters, 2013; Brilha, 2004; Schmidt, 2008; Teixeira, 2002). Por outras palavras, os jornalistas esforçam-se por transformar o saber científico em algo de interesse para o cidadão comum e os cientistas tentam responder aos jornalistas com mais ou menos competências comunicativas (Allgaier et al., 2013; Brilha, 2004; Schmidt, 2008; Teixeira, 2002). Neste contexto, surgem novas questões a equacionar, como o facto de os jornalistas passarem a desempenhar o papel de críticos do campo científico e de se aproximarem demasiado das fontes, perdendo a sua independência.

Estudos desenvolvidos sobre a mediatização da saúde em Portugal apontam para uma acentuada presença de fontes governamentais (ou oficiais) e de fontes especializadas institucionais que representam organizações prestadoras de saúde: "a forte dependência das fontes especializadas e institucionais imprime uma dada forma às 
informações sobre saúde tratadas pelos média" (Lopes, Ruão, Marinho e Araújo, p. 133). Isto acaba por influenciar a forma como estas são recebidas pelos públicos e as atitudes que estes tomam após a receção da notícia.

Portanto, o panorama aponta para o facto de os média se fazerem valer sempre das mesmas fontes de informação, escolhendo aquelas que entendem a dificuldade de transmitir informação sobre saúde: "os jornalistas tendem a recorrer a fontes oficiais e especializadas, ou seja, aquelas que apresentam um registo da ordem do 'pensar', excluindo quase sempre o cidadão comum e o paciente ou seu familiar, que têm um discurso mais da ordem do 'sentir'” (Lopes, Ruão, Marinho e Fernandes, 2013, p. 598). Assim sendo, no caso do Jornalismo em saúde, os média tendem a falar com as fontes que representam um poder dominante, promovendo a existência de confrarias e de elites, assim como a existência de grupos de fontes deixadas à margem e no silêncio (Lopes, 2007).

\section{O JORNALISMO EM TEMPOS DE CRISE DE SAÚdE PÚBLICA: A COVID-19 EM PORTUGAL}

Em contexto pandémico, os média - e o Jornalismo em particular - conquistaram um papel primordial na sociedade, representando uma ponte entre o campo da saúde e a sociedade (Gomes, 2019). Esta função de mediador reforça também o papel de educador para a saúde (Friedman, Tanner e Rose, 2013; Hinnant e Len-Rios, 2009; Tanner et al., 2015), pelo que os meios de comunicação devem procurar adequar as informações que produzem ao seu público (Ratzan e Parker, 2006).

Em momento de mudanças nas rotinas de produção noticiosa, cabe ao Jornalismo adaptar-se às necessidades. Num estudo espanhol sobre a cobertura mediática da COVID-19, concluiu-se que, em contexto de alerta geral, como é o caso desta pandemia, o interesse do público sobre o assunto aumenta consideravelmente (Lázaro-Rodríguez e Herrera-Viedma, 2020). Esta conclusão é corroborada por outra investigação espanhola que confirma que este interesse tem consequências diretas nas decisões dos média, nomeadamente no aumento do espaço que estes dedicam ao tema (CostaSánchez e López-Garcia, 2020). Além disso, denota-se que cidadãos habitualmente 
menos interessados, aumentam o seu consumo de notícias (Casero-Ripollés, 2020), pelo que o valor da informação científica adquire um novo reconhecimento enquanto fonte de conhecimento sobre a COVID-19 (Lázaro-Rodriguez e Herrera, 2020).

Portanto, denota-se uma crescente importância do público no processo de produção noticiosa. É nesta linha de pensamento que, como referimos atrás, o Jornalismo se manifesta como um modo de exercício da cidadania (Casero-Ripollés, 2020; Kovach e Rosenstiel, 2007, Martins, 2010). Partimos do princípio de que a mediatização da COVID19 pode vir a alterar alguns aspetos da realidade conhecida até então, mas esta mudança pode ser pontual e limitada ao momento que se vive com esta pandemia.

Um outro aspeto que deverá ser tido em conta na cobertura noticiosa da COVID-19 será a mediatização da morte enquanto consequência a evitar. Uma vez mais, importa equacionar os objetivos do Jornalismo em saúde. Se cabe a este Jornalismo informar a população sobre questões relacionadas com a saúde - de modo a melhorar o seu conhecimento em relação ao seu bem-estar físico e mental - cabe-lhe também o relato rigoroso dos casos de rutura extrema: a morte (Gomes e Lopes, 2016).

De facto, o modo como se encara a morte foi mudando com o tempo. Atualmente, evidencia-se uma alteração do próprio espaço: "a morte como acontecimento da vida passou do domínio familiar para o domínio dos técnicos de saúde" (Macedo, 2010, 197). Neste contexto, o próprio Jornalismo foi-se adaptando, na medida em que "as emoções e sentimentos tornaram-se elemento central nas sociedades ocidentais" (Vilaça, 2013, 40), pelo que "descrever e relatar emoções tornou-se parte da comunicação social, da esfera pública e privada" (Vilaça, 2013, p.40). O discurso jornalístico, sensível e apoiado por testemunhos pessoais que "transmitem informação pormenorizada sobre temas difíceis, como a morte ou a doença", toca o público "de uma forma que outros estilos noticiosos não conseguem" (Araújo e Lopes, 2013, p. 17).

\section{METODOLOGIA}

Com o objetivo de contribuir para uma melhor compreensão da cobertura mediática da COVID-19 em Portugal, desenvolveu-se um estudo sobre os textos noticiosos publicados 
em jornais portugueses de expressão online, dando-se especial atenção às fontes de informação citadas. Para isso, procurou-se, então, responder à questão de partida: De que modo é mediatizada a COVID-19 no jornalismo online português?

Quanto à seleção das unidades de análise, optou-se pela amostragem não probabilística por semanas compostas. Partiu-se da análise dos textos noticiosos sobre a COVID-19 em quatro edições online: Jornal de Notícias, Público, Observador e Notícias ao Minuto. Os jornais online foram selecionados por forma a incluir edições com expressão exclusivamente online ou com edição em papel, jornais de referência, assim como jornais de cariz mais popular.

Para selecionar os textos, acedeu-se aos vários jornais no período da tarde, tendo em consideração que as conferências de imprensa da Direção-Geral da Saúde ocorriam à hora do almoço e configuravam automaticamente um motivo de noticiabilidade. Para esta seleção foram apenas escolhidos os primeiros dez textos em acesso aberto da primeira página de cada jornal. O período de análise decorreu entre o dia 1 de abril e o dia 12 de maio de 2020.

Desta seleção resultaram 280 artigos noticiosos. Trata-se de um estudo de mapeamento, pelo que se privilegiou a análise quantitativa dos dados, centrada na estatística descritiva univariada. Assim, nos artigos selecionados, teve-se em conta as seguintes variáveis: temática, tipo de artigo, autoria do texto, presença de fontes de informação, número de fontes de informação. Para perceber melhor as fontes de informação citadas nos textos, houve espaço para uma análise qualitativa, desenvolvendo-se uma breve análise ao conteúdo dos artigos noticiosos.

O método comparativo foi também uma constante neste trabalho, na medida em que, durante a análise dos dados, esteve implícita uma comparação relativamente ao modo como os quatros jornais mediatizaram a COVID-19. Procurou-se, pois, "descobrir regularidades, perceber deslocamentos e transformações (...) identificando continuidades e descontinuidades, semelhanças e diferenças" (Schneider e Schimitt, 1998, p. 49). 


\section{MEDIATIZAÇÃO DA COVID-19: O QUE FOI DITO? QUEM FALOU?}

\subsection{UM JORNALISMO DE NÚMEROS}

No que diz respeito à temática dos artigos noticiosos estudados, evidenciou-se uma tendência para se apresentar a contagem de infetados e de mortos pelo novo Coronavírus, assim como para se noticiar as medidas políticas de controlo e prevenção da COVID-19. Conforme se confirma pelo quadro com a distribuição das temáticas por jornal, dos 280 artigos noticiosos, 59 são sobre a contagem de infetados, mortos e recuperados e 58 são sobre medidas do Governo para travar a pandemia.

Tabela 1. Distribuição das temáticas por jornal.

\begin{tabular}{|l|c|c|c|c|c|}
\hline Temática & $\begin{array}{c}\text { Jornal de } \\
\text { Notícias }\end{array}$ & Público & Observador & $\begin{array}{c}\text { Notícias ao } \\
\text { Minuto }\end{array}$ & Total \\
\hline Contagem & 10 & 14 & 17 & 18 & $\mathbf{5 9}$ \\
\hline Medidas & 15 & 14 & 15 & 14 & $\mathbf{5 8}$ \\
\hline Outras & 13 & 6 & 5 & 14 & $\mathbf{3 8}$ \\
\hline Social & 13 & 6 & 9 & 2 & $\mathbf{3 0}$ \\
\hline Política & 3 & 6 & 6 & 8 & $\mathbf{2 3}$ \\
\hline Consequências & 7 & 4 & 4 & 3 & $\mathbf{1 8}$ \\
\hline Investigação & 4 & 4 & 1 & 7 & $\mathbf{1 6}$ \\
\hline Economia & 1 & 6 & 6 & 2 & $\mathbf{1 5}$ \\
\hline Doença & 1 & 6 & 3 & 0 & $\mathbf{1 0}$ \\
\hline Educação & 0 & 1 & 2 & 1 & $\mathbf{4}$ \\
\hline Desporto & 2 & 0 & 1 & 0 & $\mathbf{3}$ \\
\hline Tratamentos & 1 & 1 & 0 & 0 & $\mathbf{2}$ \\
\hline Emprego & 0 & 2 & 0 & 0 & $\mathbf{2}$ \\
\hline Religião & 0 & 0 & 1 & 1 & $\mathbf{2}$ \\
\hline Total & $\mathbf{7 0}$ & $\mathbf{7 0}$ & $\mathbf{7 0}$ & $\mathbf{7 0}$ & $\mathbf{2 8 0}$ \\
\hline
\end{tabular}

De facto, como refere Oliveira (2005), "a morte é, nos media, uma experiência velha" já que "o carácter de noticiabilidade do fim da vida acompanhou toda a história do jornalismo, sendo critério de tratamento informativo de acidentes, catástrofes e crimes" (2005, p. 1952). Dia após dia, os meios de comunicação dedicam-se a atualizar o número de mortos resultantes da pandemia e familiarizam o público com esta realidade (Gomes e Lopes, 2016). 
Aos longo das várias semanas em análise, somaram-se títulos como "Há 187 mortes por Covid-19 em Portugal. Mais de oito mil infetados" (Jornal de Notícias, 1 de abril), "Covid19: Portugal tem 187 mortes e 8251 infectados" (Público, 1 de abril), "Boletim DGS. Curva dos novos casos volta a descer no dia em que se registaram mais mortes no país" (Observador, 1 de abril), “Morreram 409 pessoas de covid-19 em Portugal. Há 13.956 casos confirmados" (Público, 9 de abril), "Boletim DGS. 13.956 casos e mais 29 mortos. Portugal ultrapassa as 400 vítimas mortais" (Observador, 9 de abril), "Covid-19. Há 13.956 infetados em Portugal. Já morreram 409 pessoas" (Notícias ao Minuto, 9 de abril) ou "Mortes em tempo de Covid ultrapassam ano letal de 2018" (Jornal de Notícias, 25 de abril).

Um outro aspeto a referir no que diz respeito à contagem de mortos por COVID-19 é a importância dada aos números da vizinha Espanha. Vários foram os textos cujos títulos dão conta da mortalidade por Coronavírus neste país: "Espanha ultrapassa os $100 \mathrm{mil}$ infetados. E regista mais 864 mortos" (Notícias ao Minuto, 1 de abril), "Morreram mais 683 pessoas em Espanha e superam-se as 15 mil mortes" (Jornal de Notícias, 9 de abril), “Covid-19: Espanha ultrapassa a cifra dos 15 mil mortos" (Notícias ao Minuto, 9 de abril), "Número de mortes volta a subir em Espanha. Foram 378 nas últimas 24h" (Notícias ao Minuto, 25 de abril) e "Espanha regista mesmo número de mortos há dois dias consecutivos: 164" (Público, 5 de maio),

Esta variável temática também permitiu comprovar o peso político e económico que a COVID-19 tem na sociedade portuguesa retratada nos jornais online. A par das notícias sobre questões políticas (23) e económicas (15), estão também as notícias sobre as consequências da pandemia na sociedade (18) e sobre investigações em desenvolvimento para a criação de uma vacina contra este novo Coronavírus (16). Deste quadro, destacam-se, ainda, os reduzidos valores de textos sobre tratamentos (2), efeitos da pandemia na educação (4), no emprego (2) e na religião (1).

Se se analisar a distribuição das temáticas por jornais, conclui-se que todos se concentram nos mesmos assuntos -contagem, medidas, social e outras ${ }^{2}-$ apesar de $^{2}$

\footnotetext{
${ }^{2}$ Este indicador comporta notícias publicadas sobre temáticas não relacionadas com a COVID-19.
} 
alguns se destacarem em certas temáticas: o Notícias ao Minuto diferencia-se por uma aposta em textos sobre investigação (7), o Público e o Observador distinguem-se por tratarem de assuntos relacionados com a Economia (6 artigos em cada um dos jornais). O Jornal de Notícias publica mais textos noticiosos sobre as consequências (7) do que os restantes jornais.

\subsection{AS NOTÍCIAS DOS JORNALISTAS}

A mediatização da COVID-19 em Portugal seguiu os parâmetros habituais do Jornalismo generalista e do próprio Jornalismo em saúde. Regista-se uma clara predominância de notícias (227), em detrimento de formatos mais desenvolvidos, como a reportagem (39), ou mais personalizados como a crónica (6) e a entrevista (2).

Um olhar mais atento ao tipo de artigo por jornal, permite concluir que o Público é o jornal que mais recorre a reportagens, com 20 casos, seguindo-se o Jornal de Notícias, com 10 casos. O Observador é o único que publica ${ }^{3}$ artigos de opinião sobre o novo Coronavírus na primeira página. É igualmente este meio de comunicação o único a publicar entrevistas. Também o Jornal de Notícias se diferencia por publicar uma sondagem.

Tabela 2. Tipo de artigo por jornal.

\begin{tabular}{|l|c|c|c|c|c|}
\hline Tipo de artigo & $\begin{array}{c}\text { Jornal de } \\
\text { Notícias }\end{array}$ & Público & Observador & $\begin{array}{c}\text { Notícias ao } \\
\text { Minuto }\end{array}$ & Total \\
\hline Notícia & 55 & 50 & 55 & 67 & $\mathbf{2 2 7}$ \\
\hline Reportagem & 10 & 20 & 7 & 2 & $\mathbf{3 9}$ \\
\hline Crónica/Opinião & 0 & 0 & 6 & 0 & $\mathbf{6}$ \\
\hline Outro & 4 & 0 & 0 & 1 & $\mathbf{5}$ \\
\hline Entrevista & 0 & 0 & 2 & 0 & $\mathbf{2}$ \\
\hline Sondagem & 1 & 0 & 0 & 0 & $\mathbf{1}$ \\
\hline Total & $\mathbf{7 0}$ & $\mathbf{7 0}$ & $\mathbf{7 0}$ & $\mathbf{7 0}$ & $\mathbf{2 8 0}$ \\
\hline
\end{tabular}

A autoria dos textos noticiosos foi outra das variáveis analisadas neste estudo. Os dados revelam que grande parte dos textos são atribuídos a um jornalista (171) que, em espaço

\footnotetext{
${ }^{3}$ Importa lembrar que este estudo só contabiliza as primeiras 10 notícias de cada página.
} 
próprio, é identificado como autor. Existe, contudo, um elevado número de artigos que são replicados de agências de comunicação, não havendo, à partida, tratamento por parte do meio de comunicação que publica a notícia. Esta situação regista-se em 50 artigos, sendo 31 casos no Notícias ao Minuto. Este é, também, o meio de comunicação que mais publica textos com autoria atribuída à redação (22 casos), não se podendo, assim, identificar o autor do texto. Apesar de ser um valor bem mais reduzido, registamse 17 artigos sem referência aos autores, sendo 9 dos casos no Jornal de Notícias.

Tabela 3. Autoria dos artigos noticiosos por jornal.

\begin{tabular}{|c|c|c|c|c|c|}
\hline Autoria Jornal & $\begin{array}{l}\text { Jornal de } \\
\text { Notícias }\end{array}$ & Público & Observador & $\begin{array}{l}\text { Notícias ao } \\
\text { Minuto }\end{array}$ & Total \\
\hline Jornalistas & 43 & 58 & 53 & 17 & 171 \\
\hline Agências & 6 & 5 & 8 & 31 & 50 \\
\hline Redação & 11 & 5 & 3 & 22 & 41 \\
\hline Sem referência & 9 & 2 & 6 & 0 & 17 \\
\hline Outro & 1 & 0 & 0 & 0 & 1 \\
\hline Total & 70 & 70 & 70 & 70 & 280 \\
\hline
\end{tabular}

\subsection{FONTES POLÍTICAS EM TEXTOS DE SAÚDE}

No que diz respeito às fontes de informação, destaca-se o facto de a grande maioria dos textos ter referência a fontes. Dos 280 artigos, apenas 39 não têm indicação da origem da informação. Este dado é importante na análise, pois reflete uma preocupação dos jornalistas e dos meios de comunicação em atribuir responsabilidades relativamente às informações publicadas.

Tabela 4. Presença de fontes por jornal.

\begin{tabular}{|c|c|c|c|c|c|}
\hline Presença de fontes Jornal & $\begin{array}{l}\text { Jornal de } \\
\text { Notícias }\end{array}$ & Público & Observador & $\begin{array}{l}\text { Notícias ao } \\
\text { Minuto }\end{array}$ & Total \\
\hline Com fontes & 61 & 59 & 61 & 60 & 241 \\
\hline Sem fontes & 9 & 11 & 9 & 10 & 39 \\
\hline Total & 70 & 70 & 70 & 70 & 280 \\
\hline
\end{tabular}

Apesar deste dado positivo, a tabela 5 permite perceber que grande parte dos textos apenas apresenta uma fonte de informação (152 textos). Os resultados vão diminuindo 
conforme o número de fontes aumenta. Este dado é um pouco mais inquietante, uma vez que evidencia uma falta de contraditório. Por outras palavras, as fontes ouvidas são únicas e os seus pontos de vista são exclusivos nos artigos noticiosos, o que revela uma ausência de outras perspetivas. Embora esta ideia se aplique a todas as áreas do Jornalismo, no caso particular do Jornalismo em saúde, este facto torna-se mais grave, por se tratar de uma área tão específica e que, assim, carece de maiores explicações para o público.

Continuando a análise da tabela 5, pode-se fazer ainda algumas referências no que diz respeito ao comportamento de cada órgão de comunicação social. No que se refere à ausência de fontes, os dados apontam para um comportamento muito semelhante em todos os jornais, variando os valores entre 9 e 11 artigos sem fontes. Verifica-se, pois, que o Notícias ao Minuto e o Jornal de Notícias são aqueles que mais publicam textos com apenas uma fonte de informação, registando-se 47 e 40 fontes, respetivamente. Por seu turno, o Público é o jornal que mais publica textos com referência a várias fontes -apresentando 11 artigos com três fontes e 10 artigos com 5 ou mais fontes- e aquele que também regista mais artigos sem qualquer fonte (11 textos).

Tabela 5. Número de fontes nos artigos noticiosos, por jornal.

\begin{tabular}{|l|c|c|c|c|c|}
\hline No de fontes & $\begin{array}{c}\text { Jornal de } \\
\text { Notícias }\end{array}$ & Público & Observador & $\begin{array}{c}\text { Notícias } \\
\text { ao Minuto }\end{array}$ & Total \\
\hline Uma fonte & 40 & 27 & 38 & 47 & $\mathbf{1 5 2}$ \\
\hline Duas fontes & 9 & 10 & 8 & 11 & $\mathbf{3 8}$ \\
\hline Três fontes & 6 & 11 & 8 & 1 & $\mathbf{2 6}$ \\
\hline Quatro fontes & 1 & 1 & 5 & 0 & $\mathbf{7}$ \\
\hline Cinco ou mais fontes & 5 & 10 & 2 & 1 & $\mathbf{1 8}$ \\
\hline Sem fontes & 9 & 11 & 9 & 10 & $\mathbf{3 9}$ \\
\hline Total & $\mathbf{7 0}$ & $\mathbf{7 0}$ & $\mathbf{7 0}$ & $\mathbf{7 0}$ & $\mathbf{2 8 0}$ \\
\hline
\end{tabular}

Contrariamente aos estudos sobre Jornalismo em saúde e fontes de informação que foram referidos no enquadramento teórico deste artigo, os dados recolhidos apontam para um cenário distinto, no que diz respeito à cobertura noticiosa da COVID-19 em Portugal. Embora se trate de um conjunto de artigos noticiosos na área da saúde, as fontes de informação mais identificadas nos textos não pertencem a esta área. Pelo 
contrário, são as fontes políticas que dominam, nomeadamente com a participação assídua do primeiro-ministro, António Costa, do presidente da República, Marcelo Rebelo de Sousa, e de representantes ou deputados de outros partidos. Esta forte presença de fontes políticas justifica-se pelo elevado número de artigos sobre medidas e políticas ${ }^{4}$ do Governo para o controlo e prevenção da doença no país.

Portanto, os dados permitem referir que se mantêm as elites de poder referidas no enquadramento teórico, no que diz respeito a fontes oficiais, que respondem pelo Governo. Contudo, seria de esperar uma maior participação de fontes oficiais do campo da saúde, nomeadamente, a Ministra da Saúde, Marta Temido, e a Diretora-Geral da Saúde, Graça Freitas. Ainda que ambas sejam citadas algumas vezes, não têm o mesmo protagonismo que tem o Primeiro-Ministro, António Costa. Nesta análise, nota-se, igualmente, uma forte presença de documentos oficiais, como é o caso dos boletins diários do Ministério da Saúde. A reduzida presença da Ministra da Saúde e da DiretoraGeral da Saúde enquanto fontes de informação nas notícias, pode ser explicada pelo facto de os jornais citarem antes os boletins que ambas apresentavam ao país diariamente em conferência de imprensa. Por compilarem os dados diários - como a contagem de infetados, mortos e recuperados - de uma forma sistemática e em vários formatos, estes boletins configuravam uma fonte atraente de informação para os jornalistas, sobrepondo-se às figuras do Ministério da Saúde e da Direção-Geral da Saúde.

\section{CONCLUSÕES}

Com esta investigação, procurou-se contribuir para uma melhor compreensão da cobertura mediática da COVID-19 em Portugal. Dando especial atenção às fontes de informação, desenvolveu-se um estudo sobre os textos noticiosos publicados em quatro jornais portugueses de expressão online.

A falta de conhecimento por parte da comunidade científica mundial sobre este novo Coronavírus gerou, inevitavelmente, um interesse especial na sociedade. Alimentados

\footnotetext{
${ }^{4}$ Rever tabela 1.
} 
por esse interesse e com a responsabilidade social de informar a população, os média trabalharam quase exclusivamente sobre este assunto entre os meses de abril e maio. Centraram-se na contagem de infetados e mortos por COVID-19, assim como procuraram divulgar as medidas apresentadas pelo Governo para o controlo e prevenção da doença.

No processo de produção noticiosa sobre o novo Coronavírus, as fontes de informação adquirem um papel fundamental e contrariam as tendências de mediatização da saúde anteriores à pandemia. Embora se trate de um conjunto de artigos noticiosos na área da saúde, os dados recolhidos apontam para a forte presença de fontes de informação externas a este campo, evidenciando-se as fontes políticas, que representam o Governo ou os partidos da oposição. Confirma-se, portanto, a existência de uma elite que reflete uma falta de variedade e de quantidade de fontes nos artigos sobre COVID-19. A informação tem quase sempre a mesma origem e não há diversidade de pontos de vista, parecendo desvalorizar-se o princípio do contraditório.

Em jeito de conclusão, se o Jornalismo trabalha em prol da saúde dos indivíduos e se lhe é associada uma responsabilidade social, é fundamental que o faça de um modo direto e proactivo. Neste contexto, torna-se imperativo apostar num estudo mais aprofundado sobre a qualidade do Jornalismo que se desenvolve no campo da saúde, assim como é imprescindível confrontar os protagonistas deste processo -jornalistas, fontes e cidadão comum- com os resultados desta discussão.

Ainda assim, importa reforçar que se trata de uma investigação em curso, pelo que são apontados resultados preliminares de um trabalho que se quer mais desenvolvido no tempo e no espaço.

\section{REFERÊNCIAS}

Allgaier, J., Dunwoody, S., Brossard, D., Yin-Yueh, L. e Peters, H. (2013). Journalism and social media as means of observing the contexts of science. BioScience, 63(4), 284-287. https://doi.org/10.1525/bio.2013.63.4.8 
Araújo, R. e Lopes, F. (2013). A construção de significação através da emoção. Revista Comunicando - Tecnologias de informação, novos media e literacia digital, 2, 17-26. Retirado de http://www.revistacomunicando.sopcom.pt/edicao/37

Bardoel, J. e d'Haenens, L. (2004). Media responsability and accountability: new conceptualizations and practices. Communications, 29(1), 5-25.

https://doi.org/10.1515/comm.2004.007

Brilha, J. (2004). A Geologia, os geólogos e o manto da invisibilidade. Comunicação e Sociedade, 6, 257-265. https://doi.org/10.17231/comsoc.6(2004).1238

Broersma, M., den Herder, B. e Schohaus, B. (2013). A question of power: the changing dynamics between journalists and sources. Journalism Practice, 7(4), 388-395. https://doi.org/10.1080/17512786.2013.802474

Casero-Ripollés, A. (2020). Impact of Covid-19 on the media system. Communicative and democratic consequences of news consumption during the outbreak. El Profesional de la Información, 29(2), e290223.

Costa-Sánchez, C. e López-García, X. (2020). Comunicación y crisis del coronavirus en España. Primeras lecciones. El profesional de la información, 29(3), e290304.

Eide, M. (2014). Accounting for Journalism. Journalism Studies, 15(5), 679-688. https://doi.org/10.1080/1461670X.2014.891856

Elliott, D. (2015). Journalism ethics. Em J. Britt Holbrook (Ed.), Ethics, science, technology, and engineering: a global resource (pp. 629-634). Farmington Hills: Macmillan.

Friedman, D. B., Tanner, A. e Rose, I. D. (2013). Health journalists' perceptions of their communities and implications for the delivery of health information in the news. Journal of Community Health, 39(2), 378-385. https://doi.org/10.1007/s10900-013$\underline{9774-x}$ 
Gomes, E. e Lopes, F. (2016). Doença do legionário: da mediatização da doença à contagem das mortes. Em M. L. Martins, M. L. Correia e P. Vaz (Eds.), Figurações da morte nos média e na cultura: entre o estranho e o familiar. CECS.

Gomes, S. (2019). Jornalismo e prevenção em saúde: retratos da imprensa portuguesa entre 2012 e 2014. Tese de Doutoramento, Universidade do Minho, Braga.

Gomes, S. (março, 2020). A Saúde, o Jornalismo e a Covid-19. Communitas, think tank. Retirado de http://www.communitas.pt/ideia/a-saude-o-jornalismo-e-a-covid-19/ Hallin, D. C. e Briggs, C. L. (2014). Transcending the medical/media opposition in research on news coverage of health and medicine. Media, Culture \& Society, 37(1), 85-100. https://doi.org/10.1177/0163443714549090

Hinnant, A. e Len-Rios, M. (2009). Tacit understanding of health literacy: Interview and survey research with health journalists. Science Communication, 31(1), 84-115. https://doi.org/10.1177/1075547009335345

Kovach, B. e Rosenstiel, T. (2007). The elements of journalism: What newspeople should know and the public should expect. New York: Three Rivers Press.

Lázaro-Rodríguez, P. e Herrera-Viedma, E. (2020). Noticias sobre Covid-19 y 2019-nCoV en medios de comunicación de España: el papel de los medios digitales en tiempos de confinamiento. El Profesional de la Información, 29(3), e290302.

Lewis, J., Williams, A. e Franklin, B. (2008). Four rumours and an explanation: a political economic account of journalists' changing newsgathering and reporting practices. Journalism Practice, 2(1), 27-45. https://doi.org/10.1080/17512780701768493

Lopes, F. (2007). A TV das elites. Porto: Campo das Letras.

Lopes, F., Ruão, T., e Marinho, S. (2010). Gripe A na Imprensa Portuguesa: uma doença em notícia através de uma organizada estratégia de comunicação. Observatorio (OBS*), 4(4). https://doi.org/10.15847/obsOBS442010442 
Lopes, F., Ruão, T., Marinho, S. \& Araújo, R. (2012). A media pandemic: Influenza A in Portuguese newspapers. International Journal of Healthcare Management, 5(1), 19-27. https://doi.org/10.1179/2047971911Y.0000000001

Lopes, F., Ruão, T., Marinho, S. e Fernandes, L. (2013). Na saúde a palavra mediática não é dos doentes. In Atas do I/ Congresso Internacional Comunicação Cognição e Media (CICOM) (pp. 598-610). Braga: Publicações da Faculdade de Filosofia da Universidade Católica Portuguesa.

Macedo, J. (2010). A Morte adiada. In Ladusãns, S. (eds.), Pessoas transparentes: questões actuais de bioética (pp. 195-208). Retirado de http://hdl.handle.net/1822/17145

Marcotte, P. e Sauvageau, F. (2006). Les journalistes scientifiques: des éducateurs? Enquête auprès des membres de l'Association des communicateurs scientifiques du Québec. Les Cahiers du Journalisme, 15, 179-195. Retirado de https://www.com.ulaval.ca/fileadmin/contenu/Cahiers Journalisme/PDF/15/11 Marc otte Sauvageau.pdf

Martins, M. (2010). Prefácio: Jornalismo e sonho de comunidade. In M. Oliveira, Metajornalismo. Quando o jornalismo é sujeito do próprio discurso (pp. 9-13). Coimbra: Grácio Editor.

Marvin, C. e Meyer, P. (2005). What kind of journalism does the public need? Em G. Overholser e K. Hall (Eds.), The press (pp. 400-411). Nova lorque: Oxford Universty Press.

Naidoo, J. e Wills, J. (1998). Practising health promotion: dilemmas and challenges. Londres: Baillière Tindall.

Oliveira, M. (2005). Olhando a morte dos outros. In Repensar os media: novos contextos da comunicação e da informação - Livro de Actas - 4 SOPCOM (pp. 19521962). Aveiro: Universidade de Aveiro.

Pavlik, J. (2001). Journalism and new media. Nova Iorque: Columbia University Press. 
Raaum, O. (1986). Pressens tøyelige etikk. Journalisters yrkesmoral og selvjustis [The Elastic Ethics of the Press]. Oslo: Universitetsforlaget.

Raaum, O. (1999). Pressens tøyelige etikk. Journalisters yrkesmoral og selvjustis [The Elastic Ethics of the Press]. Oslo: Universitetsforlaget.

Ratzan, S. C. e Parker, R. M. (2006) Health literacy - identification and response. Journal of Health Communication, 11(8), 713-715. https://doi.org/10.1080/10810730601031090

Ratzan, S. C. (2002). Public health at risk: media and political malpractice. Journal of health communication, 7(2), 83-85. https://doi.org/10.1080/10810730290087969

Schmidt, L. (2008). Comunicar a ciência: o papel dos media e os problemas científicoambientais. Em L. Schmidt e J. P. Cabral (Eds.), Ciência e cidadania - homenagem a Bento de Jesus Caraça (pp. 85-112). Lisboa: Imprensa de Ciências Sociais.

Schneider, S. e Schimitt, C. J. (1998). O uso do método comparativo nas Ciências Sociais. Cadernos de Sociologia, 9, 49-87. Retirado de http://files.ibijus.webnode.com.br/2000009154b6864c63f/M\%C3\%A9todo\%20Explicativo\%20-\%20Texto\%202.pdf

Schwitzer, G. (2009). Seven words (and more) you shouldn't use in medical news. Retirado de http://www.healthnewsreview.org/toolkit/tips-for-understandingstudies/7-words-and-more-you-shouldnt-use-in-medical-news/

Schwitzer, G. (2010). The future of health journalism. Public Health Forum, 18(3), 19e1-19e3. https://doi.org/10.1016/j.phf.2010.06.012

Sigal, L. (2008). Hand in hand for Korea: a peace process and denuclearization. Asian Perspective, 32(2), 5-19.

Sjøvaag, H. (2010). The reciprocity of journalism's social contract. Journalism Studies, 11(6), 874-888. https://doi.org/10.1080/14616701003644044 
Spyridou, L., Matsiola, M., Veglis, A., Kalliris, G. e Dimoulas, C. (2013). Journalism in a state of flux: Journalists as agents of technology innovation and emerging news practices. The International Communication Gazette, 75(1), 76-98.

https://doi.org/10.1177/1748048512461763

Strömback, J. (2005). In search of a standard. Four models of democracy and their normative implications for journalism. Journalism Studies, 6(3), 331-345.

https://doi.org/10.1080/14616700500131950

Tanner, A. H., Friedman, D. B. e Zheng, Y. (2015). Influences on the construction of health news: the reporting practices of local television news health journalists. Journal of Broadcasting \& Electronic Media, 59(2), 359-376.

https://doi.org/10.1080/08838151.2015.1029123g

Tavares, F. (2007). Percursos entre o Jornalismo e o Jornalismo Especializado.

Comunicação apresentada no VIII Congresso Brasileiro de Ciências da Comunicação da Região Sul - Passo Fundo. Retirado de

http://www.intercom.org.br/papers/regionais/sul2007/resumos/R0648-1.pdf

Tavares, F. (2009). O jornalismo especializado e a especialização periodística. Estudos em Comunicação, 5, 115-133. Retirado de http://www.ec.ubi.pt/ec/05/pdf/06-tavaresacontecimento.pdf

Teixeira, M. (2002). Uma visão do debate sobre as relações entre a ciência e o jornalismo. Pressupostos do Jornalismo de Ciência no Brasil, 133-141. Retirado de http://www.casadaciencia.ufrj.br/Publicacoes/terraincognita/cienciaepublico/artigos/ art10 pressupostos.pdf

Valero-Cedeño, N. J., Mina-Ortiz, J. B., Veliz-Castro, T. I., Merchán-Villafuerte, K. M., e Perozo-Mena, A. J. (2020). COVID-19: La nueva pandemia con muchas lecciones y nuevos retos. Revisión Narrativa. Kasmera, 48(1).

https://doi.org/10.5281/zenodo.3745322 
Vaughan, E. e Tinker, T. (2009). Effective health risk communication about pandemic influenza for vulnerable populations. American Journal of Public Health, 99(2), 324332.

Vilaça, R. (2013). A representação da dor na imprensa nacional: análise da relação entre os media e as fontes de informação durante a experiência de estágio no Jornal de Notícias. Dissertação de Mestrado, Universidade do Minho, Braga, Portugal. Retirado de http://hdl.handle.net/1822/29134

Wilson, A., Robertson, J., McElduff, P., Jones, A. e Henry, D. (2010). Does it matter who writes medical news stories? PLoS Med, 7(9), e1000323.

https://doi.org/10.1371/journal.pmed.1000323 